\title{
First Intraluminal Temperature Measurement during Ho:YAG-Laser Exposure at an In-Vitro URS
}

\author{
Jens Cordes*, Felix Nguyen, Karl-Dietrich Sievert \\ Clinic of Urology, University Medical Center Schleswig-Holstein, Lübeck, Germany \\ Email: Jens.Cordes@uk-sh.de
}

Received 2 November 2014; revised 5 December 2014; accepted 15 December 2014

Academic Editor: Phillip Mucksavage, University of Pennsylvania, USA

Copyright (C) 2015 by authors and Scientific Research Publishing Inc.

This work is licensed under the Creative Commons Attribution International License (CC BY). http://creativecommons.org/licenses/by/4.0/

(c) (i) Open Access

\section{Abstract}

Introduction: The laser is a high energy instrument which can melt metals like nitinol. So it is very important to know under which conditions it is dangerous to perform an endourologic lithotripsy. We measure the temperature increase during laser exposure in an underwater in-vitro ureter model. For comparison, temperatures with and without irrigation and with different distances from the laser fiber to the thermometer are measured. Materials and Methods: We used the Ho:YAGlaser (Vera Pulse ${ }^{\mathrm{TM}}$, Coherent) with a $365 \mu \mathrm{m}$ laser fiber. The settings of the laser were $0.6 \mathrm{~J}$ with a frequency of $5 \mathrm{~Hz}$ which is the minimum setting for that type of laser. The experimental setup was closely aligned with the clinical situation. A metal container was filled with $0.9 \%$ sodium chloride ( $\mathrm{NaCl}$ ) solution (Temp. $36.8^{\circ}$ ) and a catheter with an inner diameter of $4 \mathrm{~mm}$ was attached to the rim of the container. The tip of the thermometer was attached inside the catheter through a waterproof hole. The laser fiber was guided by means of a rigid URS video device (11.5 F). We had four different settings during the measurement: 1) Distance of $0.5 \mathrm{~cm}$ between the laser and the thermometer; without irrigation, 2) Distance of $0.5 \mathrm{~cm}$ between the laser and the thermometer; with irrigation, 3) Distance of $1 \mathrm{~cm}$ between the laser and the thermometer; without irrigation, 4) Distance of $1 \mathrm{~cm}$ between the laser and the thermometer; with irrigation. Results: The maximum overall temperature was recorded in the 1) and 3) setting, both featuring no irrigation. The maximum temperature was $\sim 50^{\circ} \mathrm{C}$ in both settings, with the 1 ) setting reaching the maximum temperature after 50 seconds and hence approximately twice as fast as the 3 ) setting. During measurements with a $\mathrm{NaCl}$ solution flow we couldn't detect any noticeable increase in temperature, neither at short nor at long distance between the laser fiber and the thermometer. Conclusion: There is a relevant heating in the ureter beside an endourologic lithotripsy. In our model we could reproduce a maximum heating until $\sim 5^{\circ} \mathrm{C}$ without irrigation and no heating with irrigation. Without ir-

*Corresponding author. 
rigation there is a relevant bubble formation which should be an indicator for the surgeon to stop lithotripsy due to a temperature increase which could harm surrounding tissue.

\title{
Keywords
}

\author{
YAG-Laser, Exposure, Intraluminal, Irrigation, Laser Fiber
}

\section{Introduction}

The Ho:YAG-Laser is named as the gold standard lithotripsy modality for endoscopic lithotripsy [1]. In a global study of the endourological society with 11,885 patients, $49 \%$ (5820) of the physicians used the laser as a fragmentation device beside the ureteroscopy [2].

Acute complication like a perforation of the ureter by the laser is mainly caused by the photonic and acoustic energy the laser emits. The Ho:YAG-Laser is categorized as a potentially dangerous lithotripsy device for perforation [3]. Long time complications like ureteral strictures seem to be directed by thermal and mechanical injury. So it is important to know the temperature profiles in the ureter with different conditions. The laser is a high energy instrument which can melt a metal like nitinol [4]. So it is very important to know under which conditions it is dangerous to perform an endourologic lithotripsy.

We measure how the temperature increases during laser exposure in an underwater in-vitro ureter model. For comparison we measure temperatures with and without irrigation and with different distances from the laser fiber to the thermometer.

\section{Material and Methods}

We used the Ho:YAG-laser (Vera Pulse ${ }^{\mathrm{TM}}$, Coherent) with a $365 \mu \mathrm{m}$ laser fiber. The setting of the laser was 0.6 $\mathrm{J}$ with a frequency of $5 \mathrm{~Hz}$ which is the minimum setting for that type of laser. The experimental setup was closely aligned with the clinical situation (Figure 1).

A metal container was filled with $0.9 \%$ sodium chloride $(\mathrm{NaCl})$ solution (Temp. $36.8^{\circ}$ ) and a catheter with an inner diameter of $4 \mathrm{~mm}$ was attached to the rim of the container. The tip of the thermometer was attached inside the catheter through a waterproof hole. The Laser Fiber was guided by means of a rigid URS video device (11.5 F) (Figure 2).

The above mentioned instruments were now inserted into the artificial ureter with a distance between the tip of the thermometer and the laser fiber of both $0.5 \mathrm{~cm}$ and $1 \mathrm{~cm}$ (Figure 3).

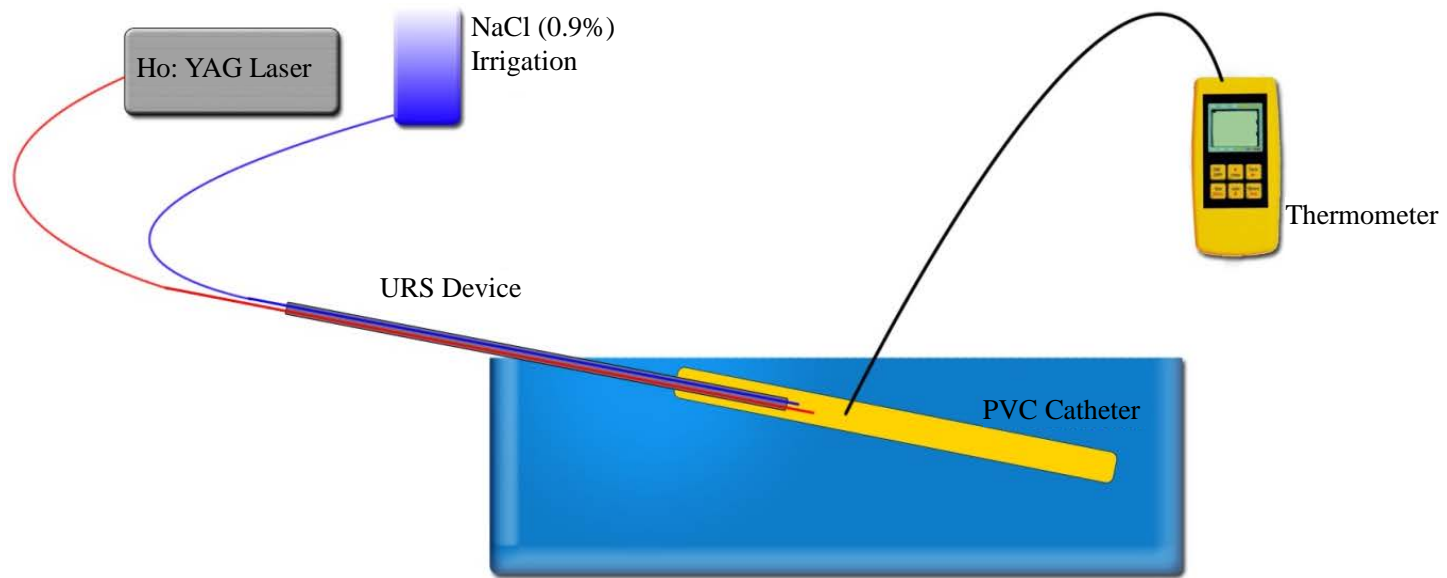

Bassin filled with $\mathrm{NaCl} 0.9 \%$

Figure 1. The schematic drawing of the experimental setup shows the URS device with the laser fiber and the intraluminal tip of the thermometer inside a catheter surrounded by $\mathrm{NaCl}$ solution. 


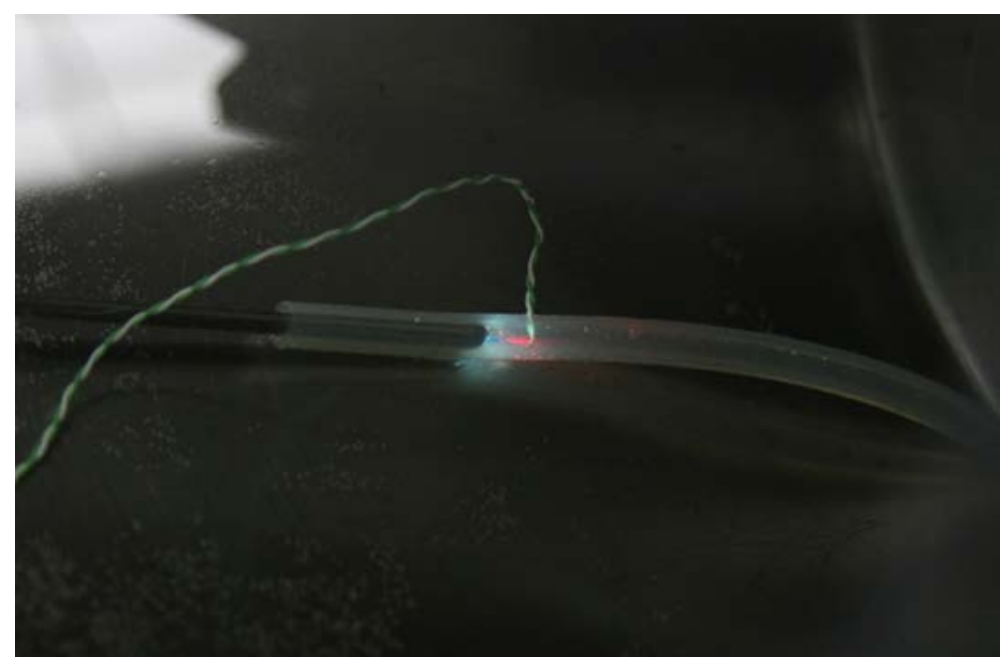

Figure 2. Artificial ureter with the probe of the thermometer (green cable) and the tip of the semirigid renoscope with the attached laser fiber.



Figure 3. View from inside the catheter through the renoscope. Both the tip of the thermometer and the laser fiber are visible.

During the measurements with irrigation, a $\mathrm{NaCl}$ solution was piped through the URS-device. The irrigation has the same height as it is commonly used in our theater. The irrigation fluid came out of our warming facility with $37^{\circ} \mathrm{C}$ (Figure 4).

We had four different settings during the measurement.

1) Distance of $\mathbf{0 . 5} \mathbf{~ c m}$ between laser and thermometer; without irrigation;

2) Distance of $\mathbf{0 . 5} \mathbf{~ c m}$ between laser and thermometer; with irrigation;

3) Distance of $\mathbf{1} \mathbf{~ c m}$ between laser and thermometer; without irrigation;

4) Distance of $\mathbf{1} \mathbf{~ c m}$ between laser and thermometer; with irrigation.

\section{Results}

The maximum overall temperature was recorded in the 1) and 3) setting, both featuring no irrigation. The maximum temperature was $50^{\circ} \mathrm{C}$ in both settings, with the 1) setting reaching the maximum temperature after 50 seconds and hence approximately twice as fast as the 3) setting (Figure 5). During measurements with a $\mathrm{NaCl}$ 


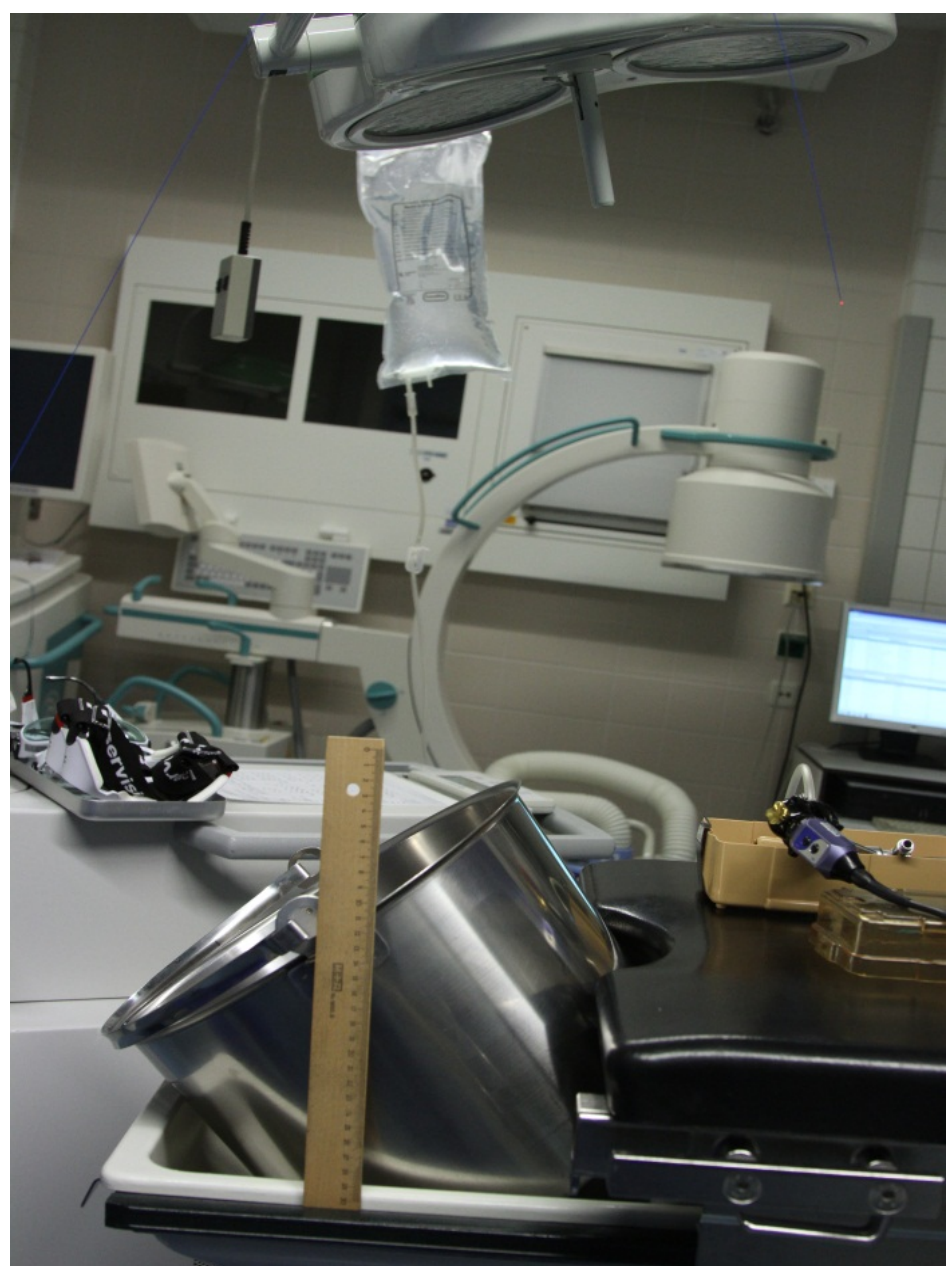

Figure 4. Photo of the experimental setup with the bassin and the irrigation fluid.



Figure 5. Four different settings: Short means $0.5 \mathrm{~cm}$ and long means $1 \mathrm{~cm}$. 
solution flow we couldn't detect any noticeable increase in temperature, neither at short nor at long distance between the laser fiber and the thermometer.

Without continuous flow as in setting 1) and 3) we saw steady bubble emergence. With continuous irrigation no bubbles were detected. The starting temperature was $35^{\circ} \mathrm{C}$ in the 1 ), $34.6^{\circ} \mathrm{C}$ in the 2), $37.0^{\circ} \mathrm{C}$ in 3 ) and $34.1^{\circ} \mathrm{C}$ in the 4) setting. The starting temperatures differ $2.9^{\circ} \mathrm{C}$ at maximum.

\section{Discussion}

This is the first intraluminal temperature measurement of an activated Ho:YAG-Laser beside an in vitro URS. Molina et al. [5] already measured the Temperature Profile of Laser Lithotripsy Activation with a thermal camera. They measured outside a ureter model and with an open ureter model with a thermal camera. They used a higher energy setting with $1 \mathrm{~J} /$ Pulse and $10 \mathrm{~Hz}$. With our model we can reproduce the external measurement with irrigation of $37.4^{\circ} \mathrm{C}$ and without irrigation of $49.5^{\circ} \mathrm{C}$. In the open model they had higher temperature levels at $49.7^{\circ} \mathrm{C}$ with irrigation and $112.4^{\circ} \mathrm{C}$ without irrigation. Maybe the distance of $0.5 \mathrm{~cm}$ to the thermometer is an explanation for this difference. Also the open ureter in our setting could be a reason.

Limitation of this in vitro study is the open ureter. In the normal clinical setting maximal irrigation is only possible when the upper tract of the ureter is not full (of $\mathrm{NaCl}$ solution, for example) or the operating surgeon uses an irrigation set. The artificial ureter is thicker than a normal ureter. The measurement only covers one setting for the energy-level and one laser fiber of $365 \mu \mathrm{m}$. Important for the physician is the bubble-emergence right in front of the laser fiber. The surgeon should be aware that steady bubble appearance could indicate a temperature increase.

\section{Conclusion}

There is a relevant heating in the ureter beside an endourologic lithotripsy. In our model we could reproduce a maximum heating until $\sim 50^{\circ} \mathrm{C}$ without irrigation and no heating with irrigation. Without irrigation there is a relevant bubble formation which should be an indicator for a physician to stop lithotripsy. There should be more studies to evaluate the temperature profile.

\section{References}

[1] Marks, A.J. and Teichman, J.M. (2007) Lasers in Clinical Urology: State of the Art and New Horizons. World Journal of Urology, 25, 227-233. http://dx.doi.org/10.1007/s00345-007-0163-X

[2] Rosette, J., Denstedt, J., Geavlete, P., Keeley, F., Matsuda, T., Pearle, M., Preminger, G. and Traxer, O. (2014) The Clinical Research Office of the Endourological Society Ureteroscopy Global Study: Indications, Complications and Outcomes in 11,885 Patients. Journal of Endourology, 28, 131-139. http://dx.doi.org/10.1089/end.2013.0436

[3] Piergiovanni, M., Desgrandchamps, F., Cochand-Priollet, B., et al. (1994) Ureteral and Bladder Lesions after Ballistic, Ultrasonic, Electrohydraulic, or Laser Lithotripsy. Journal of Endourology, 8, 293-299. http://dx.doi.org/10.1089/end.1994.8.293

[4] Cordes, J., Lange, B., Jocham, D. and Kausch, I. (2011) Destruction of Stone Extraction Basket during an in Vitro Lithotripsy-A Comparison of Four Lithotripters. Journal of Endourology, 25, 1-4. http://dx.doi.org/10.1089/end.2011.0019

[5] Molina, W.R., Silva, I.N., Donalisio da Silva, R., Gustafson, D., Sehrt, D. and Kim, F.J. (2014) Influence of Saline on Temperature Profile of Laser Lithotripsy Activation. Journal of Endourology, 26. (Epub Ahead of Print) 
Scientific Research Publishing (SCIRP) is one of the largest Open Access journal publishers. It is currently publishing more than 200 open access, online, peer-reviewed journals covering a wide range of academic disciplines. SCIRP serves the worldwide academic communities and contributes to the progress and application of science with its publication.

Other selected journals from SCIRP are listed as below. Submit your manuscript to us via either submit@scirp.org or Online Submission Portal.
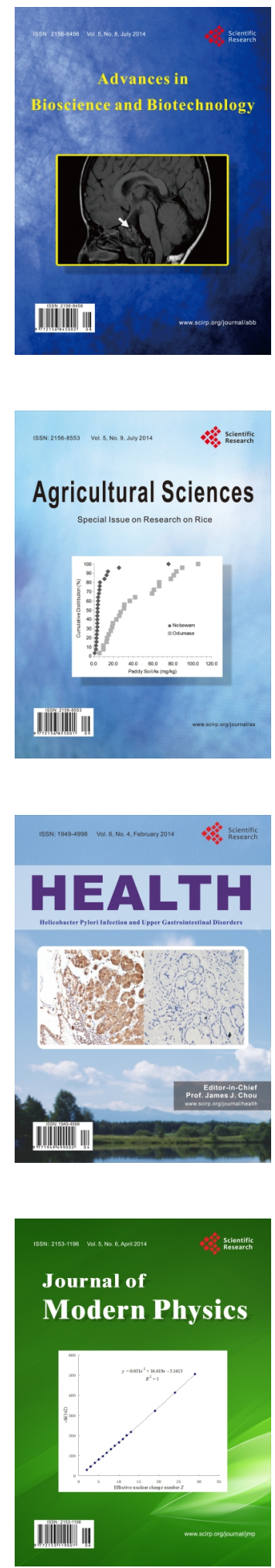
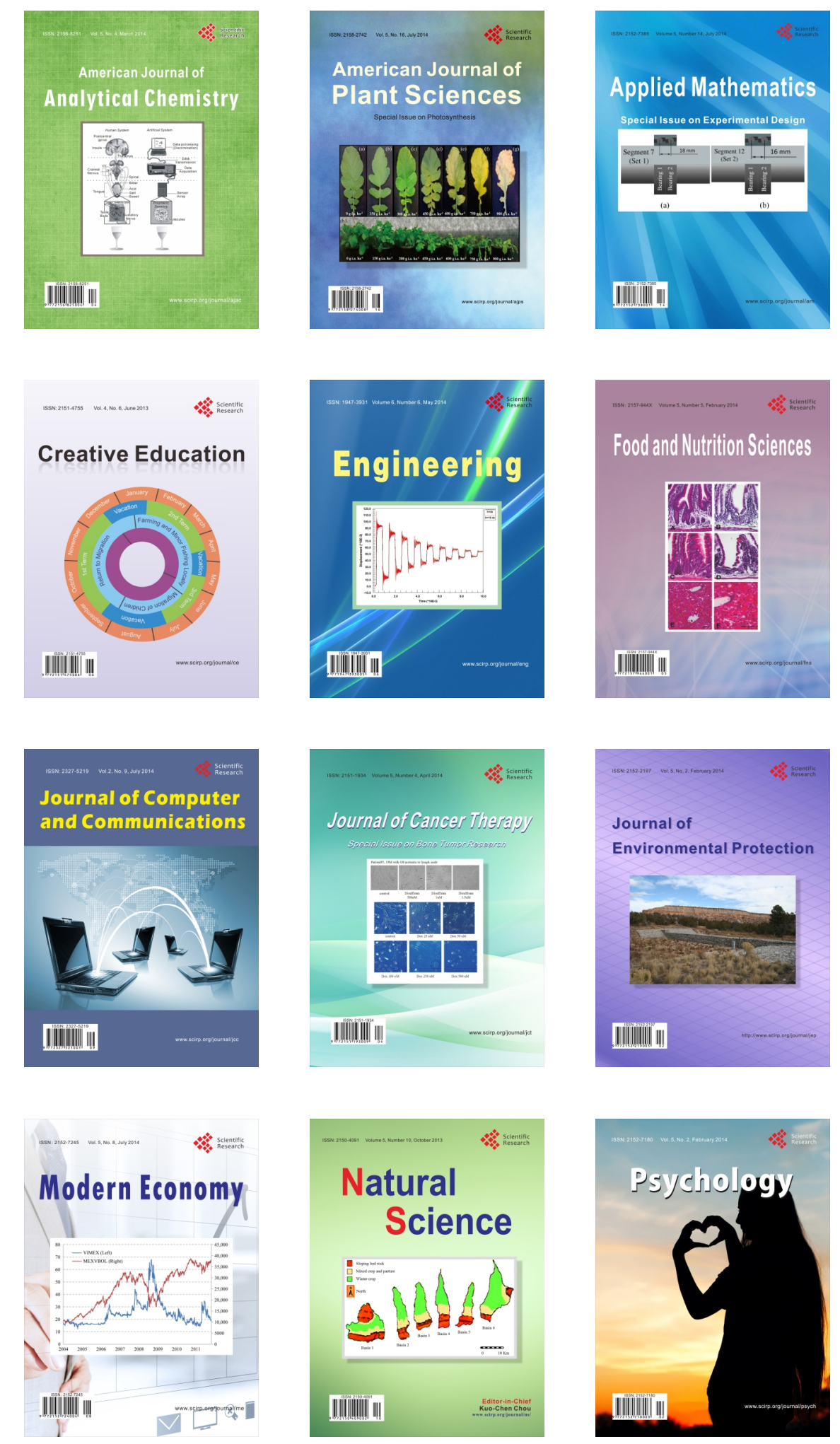